\title{
The Possibility of Using Different Variants HPLC in Determining Baclofen in Biological Objects
}

\author{
Olga A. Dukova ${ }^{a}$,

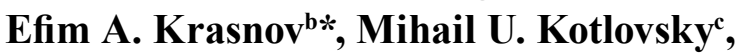 \\ Elena V. Suvorova ${ }^{a}$ and Aleksander A. Efremov ${ }^{d}$ \\ ${ }^{a}$ Krasnoyarsk Regional Bureau of Forensic Medical Expertize \\ 35 Mira, Krasnoyarsk, 660049, Russia \\ ${ }^{b}$ Siberian Medical University \\ 2 Moscow tract, building 7, block A, Tomsk, 634050, Russia \\ ${ }^{c}$ Central Research Laboratory of Voyno-Yasenetsky \\ Krasnoyarsk Medical University \\ Iz Partizana Jeleznyaka, Krasnoyarsk, 660022, Russia \\ ${ }^{d}$ Siberian Federal University \\ 79 Svobodny, Krasnoyarsk, 660041, Russia
}

Received 23.01.2015, received in revised form 16.02.2015, accepted 28.03.2015

The possibilities of determination baclofen in biological fluids (blood, urine) HPLC detection of different variants for diagnostics of poisoning baclofen are considered. For identification and quantitative determination baclofen in urine proposed a method based on HPLC-UV. For the quantitative determination baclofen in blood developed the technique HPLC-MS/MS. The developed techniques are sensitive, express, specific and accurate.

Keywords: baclofen, poisoning, HPLC-UV, HPLC-MS/MS.

(c) Siberian Federal University. All rights reserved

* Corresponding author E-mail address: krasnov.37@mail.ru 


\title{
Возможности использования \\ различных вариантов ВЭЖХ \\ при определении баклофена \\ в биологических объектах
}

\author{
О.А. Дукова ${ }^{a}$, Е.А. Краснов \\ М.Ю. Котловский ${ }^{\text {, Е.В. Суворова }}{ }^{\mathrm{a}}$, А.А. Ефремов ${ }^{\mathrm{r}}$ \\ ${ }^{a}$ Красноярское краевое бюро судебно-медичинской экспертизы \\ Россия, 660049, Красноярск, пр. Мира, 35 \\ ${ }^{6}$ Сибирский государственный медицинский университет \\ Россия, 634050, Томск, Московский тракт, 2, стр. 7, блок А \\ ${ }^{6}$ Центральная научно-исследовательская лаборатория \\ Красноярского государственного медииинского университета \\ им. проф. В.Ф. Войно-Ясенецкого \\ Россия, 660022, Красноярск, ул. Партизана Железняка, 13 \\ ${ }^{2}$ Сибирский федеральный университет \\ Россия, 660041, Красноярск, пр. Свободныий, 79
}

\begin{abstract}
Рассмотрены возможности определения баклофена в биологических жидкостях (крови, моче) методом ВЭЖХ с различными вариантами детектирования с иеелью подтверждения диагноза отравление баклофеном. Для идентификации и количественного определения баклофена в моче предложена методика на основе ВЭЖХ-УФ. Для количественного определения баклофена в крови создана методика ВЭЖХ-МС/МС. Разработанные методики чувствительны, экспрессны, специфичны и правильны.
\end{abstract}

Ключевые слова: баклофен, отравления, ВЭЖХ-УФ, ВЭЖХ-МС/МС.

\section{Введение}

Одним из лекарственных средств, имеющих немедицинское применение среди подростков в России, является баклофен, свободно продающийся в аптеках. Баклофен относится к группе веществ, влияющих на нервно-мышечную передачу [1]. В 2012 г. в отделении острых отравлений Красноярской межрайонной клинической больницы скорой медицинской помощи № 6 им. Н.С. Карповича (КМКБСМП) зафиксировано 15 случаев острых отравлений баклофеном, в 2011 г. - 16, а в 2010 г. - 23 случая. Большинство пациентов принимали баклофен для наркотического опьянения или с суицидальной целью.

Клиническая картина отравления баклофеном неспецифична, симптомы отравления могут быть схожи с таковыми при отравлении синтетическими наркотиками, алкоголем, антидепрессантами, барбитуратами и другими веществами, действующими на центральную нервную систему. В этой связи для подтверждения диагноза отравления баклофеном и последующего 
правильного лечения необходимо иметь надежные, достоверные и чувствительные методики его качественного и количественного определения в биологических жидкостях.

По химической структуре баклофен - 4-амино-3-(4-хлорфенил)-бутановая кислота. Баклофен представляет собой порошок белого цвета. Мало растворим в воде, очень мало растворим в 96\%-ном этаноле, практически не растворяется в ацетоне, диэтиловом эфире и в хлороформе [2-3]. Исходя из химических свойств баклофена, самым перспективным методом для определения баклофена признан метод ВЭЖХ с различными способами детектирования.

Анализ литературных данных показал, что комплексного исследования баклофена в химико-токсикологическом и судебно-химическом аспектах не проводилось. Существующие методики анализа баклофена в биологических объектах предусматривают использование дорогостоящих и труднодоступных реагентов и детекторов и не предназначены для рутинного анализа $[2,4,5]$. Учитывая наличие случаев острых отравлений баклофеном, в том числе и смертельных случаев, актуально систематическое исследование по разработке и оптимизации методик судебно-химического и химико-токсикологического анализа баклофена.

Целью работы являлось применение ВЭЖХ-метода с различными способами детектирования для определения баклофена в биологических жидкостях.

\section{Экспериментальная часть}

Для идентификации и количественного определения баклофена в моче использовали метод ВЭЖХ/УФ. Пробоподготовку образцов мочи, полученных от лиц с подозрением на отравление баклофеном, проводили следующим образом: к 1 мл мочи прибавляли 1 мл ацетонитрила, выдерживали в ультразвуковой ванне 15 мин при температуре $40{ }^{\circ} \mathrm{C}$ и центрифугировали при 3000 об/мин в течение 15 мин. Затем прибавляли по 0,05 г кристаллического хлорида натрия и сульфата натрия, 0,1 г сорбента C18 (Separon SGX RPS, 60 мкм) и 1 мл гексана, помещали в шейкер (S-3.02M, Латвия) на 15 мин, центрифугировали при 3000 об/мин в течение 15 мин. После этого слой гексана удаляли пипеткой, а оставшуюся жидкость пропускали через бумажный фильтр, смоченный дистиллированной водой, и выпаривали в токе теплого воздуха. Сухие остатки растворяли в 0,5 мл $0,1 \mathrm{M}$ хлороводородной кислоты и исследовали методом ВЭЖХ-УФ.

Оптимальные условия ВЭЖХ-анализа были определены в работе [6]: хроматограф Agilent Technologies 1200 (США) с многоволновым диодно-матричным детектором; колонка Phenomenex Luna 5u C18(2), 250×4,6 мм, 5мкм; предколонка Eclipse XDB-C18 4-Pack 4,6×12,5 мм, 5 мкм; температура термостата колонки $30^{\circ} \mathrm{C}$; объем пробы 20 мкл. Регистрация поглощения осуществлялась при длинах волн 220, 259, 266 и 274 нм, так как при указанных длинах волн наблюдаются максимумы в спектре поглощения баклофена. Количественное определение проводили при длине волны 220 нм. Управление прибором и обработку хроматограмм осуществляли с использованием программы ChemStation. Анализ проводили в режиме градиентного элюирования, состав элюента ацетонитрил - 10 мМ триэтиламина, состав подвижной фазы изменялся от 0 до $20 \%$ ацетонитрила. Скорость потока элюента для аналитической колонки 0,8 мл/мин.

Пробоподготовку образцов крови реализовали иным оптимальным способом. К 1 мл крови прибавляли 50 мкл водного раствора внутреннего стандарта фенибута (концентрация 1 мкг/мл, РУП «БЕЛМЕДПРЕПАРАТЫ»). Фенибут был выбран в качестве внутреннего 
Olga A. Dukova, Efim A. Krasnov... The Possibility of Using Different Variants HPLC in Determining Baclofen...

Таблица 1. Параметры MRM переходов баклофена и фенибута

\begin{tabular}{|l|c|c|c|c|}
\hline \multicolumn{1}{|c|}{ Вещество } & MRM переход & DP, B & CE, эB & CXP, B \\
\hline \multirow{5}{*}{ Баклофен } & $214 \rightarrow 151$ & 60 & 25 & 12 \\
\cline { 1 - 5 } & $214 \rightarrow 179$ & 60 & 28 & 12 \\
\cline { 1 - 5 } & $214 \rightarrow 197$ & 60 & 14 & 12 \\
\hline \multirow{2}{*}{$\begin{array}{l}\text { Фенибут } \\
\text { внутренний стандарт) }\end{array}$} & $180 \rightarrow 163$ & 60 & 13 & 13 \\
\cline { 1 - 5 } & $180 \rightarrow 145$ & 60 & 17 & 13 \\
\hline
\end{tabular}

Примечание: MRM - мониторинг множественных реакций (multiple reaction monitoring mode), DP - потенциал декластеризации (declustering potential), CE - энергия соударений (collision energy), CXP - напряжение на выходе ячейки соударений (collision cell exit potential).

стандарта ввиду схожести его химической структуры с баклофеном, который отличается от фенибута наличием атома хлора. В связи с этим можно предположить, что показатели извлечения из биологических объектов и удерживания на хроматографической колонке для баклофена и фенибута будут схожи. Далее прибавляли 0,1-0,15 мл 50\%-ного раствора трихлоруксусной кислоты, выдерживали на шейкере (S-3.02M, Латвия) 15 мин, затем центрифугировали в течение 15 мин при скорости 4000 об/мин на центрифуге типа ОПн-8 (Россия). После этого 20 мкл полученного надосадочного слоя переносили в виалу и добавляли 980 мкл дистиллированной воды.

Для построения градуировочных графиков использовали трупную кровь и мочу, предварительно проверенные на отсутствие лекарственных веществ, в которые вводили различное количество рабочего раствора баклофена (Sigma, CША) с концентрацией 1 мкг/мл.

Концентрацию баклофена в крови определяли с помощью высокоэффективного жидкостного хроматографа UltiMate 3000 (Dionex, Германия), детектором был тандемный массспектрометр с ионной ловушкой QTRAP 5500 (AB SCIEX, Канада). Условия хроматографирования: колонка Zorbax Eclipse XDB-C18 (5 мкм, $150 \times 4,6$ мм), температура термостата колонки $37^{\circ} \mathrm{C}$, подвижная фаза ацетонитрил - метанол - 0,65 мМ раствор ацетата аммония (15:15:70), изократический режим, скорость потока элюента 1 мл/мин. Объем вводимой пробы 20 мкл. Работа масс-спектрометра осуществлялась в режиме регистрации положительных ионов, ионизация электроспреем. Условия работы источника ионов: температура источника ионов $500{ }^{\circ} \mathrm{C}$, напряжение на капилляре (IS) 5,5 кB, давление газа-небулайзера (Gas 1) 50 psi, давление осушающего газа (Gas 2) 50 psi, давление газа-завесы (CUR) 25 psi. Программа обработки данных Analyst 1.5.2 (AB SCIEX, Канада), с помощью которой были подобраны параметры MRM переходов (табл. 1).

\section{Результаты и их обсуждение}

В качестве объекта для скрининга и идентификации токсиканта в химикотоксикологическом анализе используется моча, так как концентрация лекарственных, наркотических веществ и их метаболитов в моче значительно превышает их концентрации в кро- 
ви или плазме. Однако для токсикологической оценки большое значение имеет определение концентрации токсиканта именно в крови.

При исследовании методом ВЭЖХ/УФ идентификацию пика баклофена в экстракте мочи проводили по времени удерживания и УФ-спектру. Время удерживания баклофена составило 6,18 мин (рис. 1).

Метрологические характеристики методики определения баклофена в моче были изложены в предыдущей работе [7]. Разработанная ВЭЖХ-методика количественного определения баклофена в моче характеризуется специфичностью, линейностью, правильностью и повторяемостью. Уравнение зависимости аналитического сигнала от концентрации баклофена имеет вид $\mathrm{y}=29,078 \mathrm{x}-20,233$, коэффициент корреляции 0,99966. Предел количественного определения баклофена в моче составил 2 мкг/мл, который рассчитывали как наименьшую концентрацию баклофена, при которой отношение сигнал - шум составляло 10:1. Правильность методики устанавливали методом «введено-найдено» по шести концентрационным уровням градуировочного графика в трех параллельных измерениях, отклонение от истинного значения составило $0,3-10 \%$

Учитывая низкие концентрации баклофена в крови, чувствительности метода ВЭЖХ/УФ недостаточно для ее определения, поэтому был использован метод ВЭЖХ с тандемным массспектрометрическим детектированием (ВЭЖХ-МС/MC), отличающийся весьма высокой чувствительностью и возможностью с высокой селективностью определять нужный ион в области пг в режиме мониторинга заданного иона.

При исследовании баклофена в крови методом ВЭЖХ-МС/МС идентификацию пика баклофена проводили по времени удерживания пиков заданных пар ионов (родительский ион дочерний ион). Время удерживания баклофена составило 3,51 мин, внутреннего стандарта фенибута - 2,91 мин (рис. 2).

Разработанная методика количественного определения баклофена в крови характеризуется специфичностью, линейностью, правильностью, повторяемостью, низким пределом

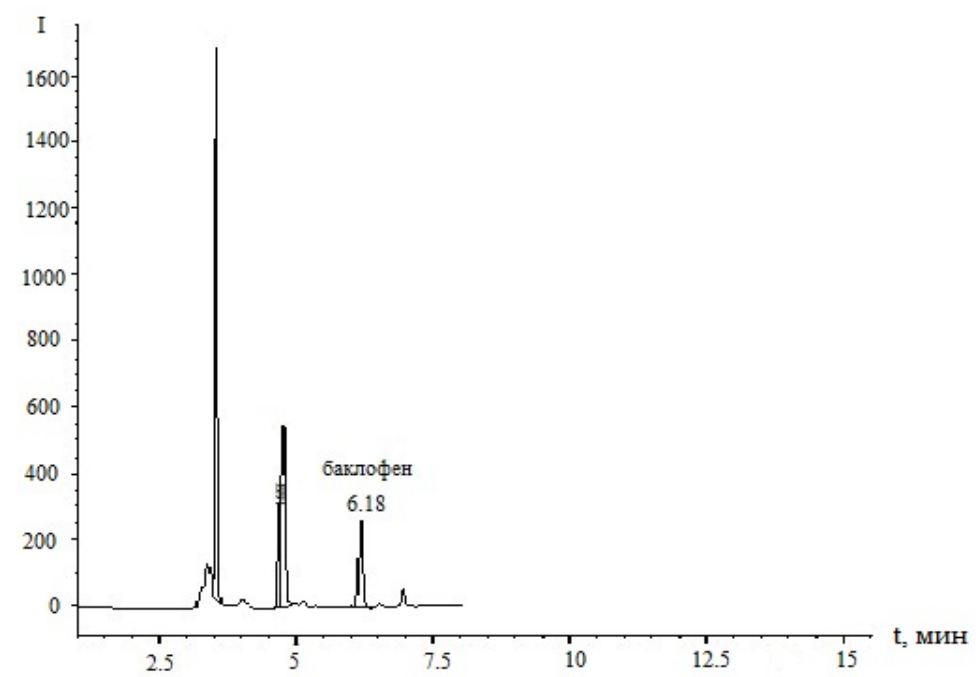

Рис. 1. Хроматограмма экстракта мочи, содержащей баклофен, концентрация баклофена 10 мкг/мл

$$
-74-
$$




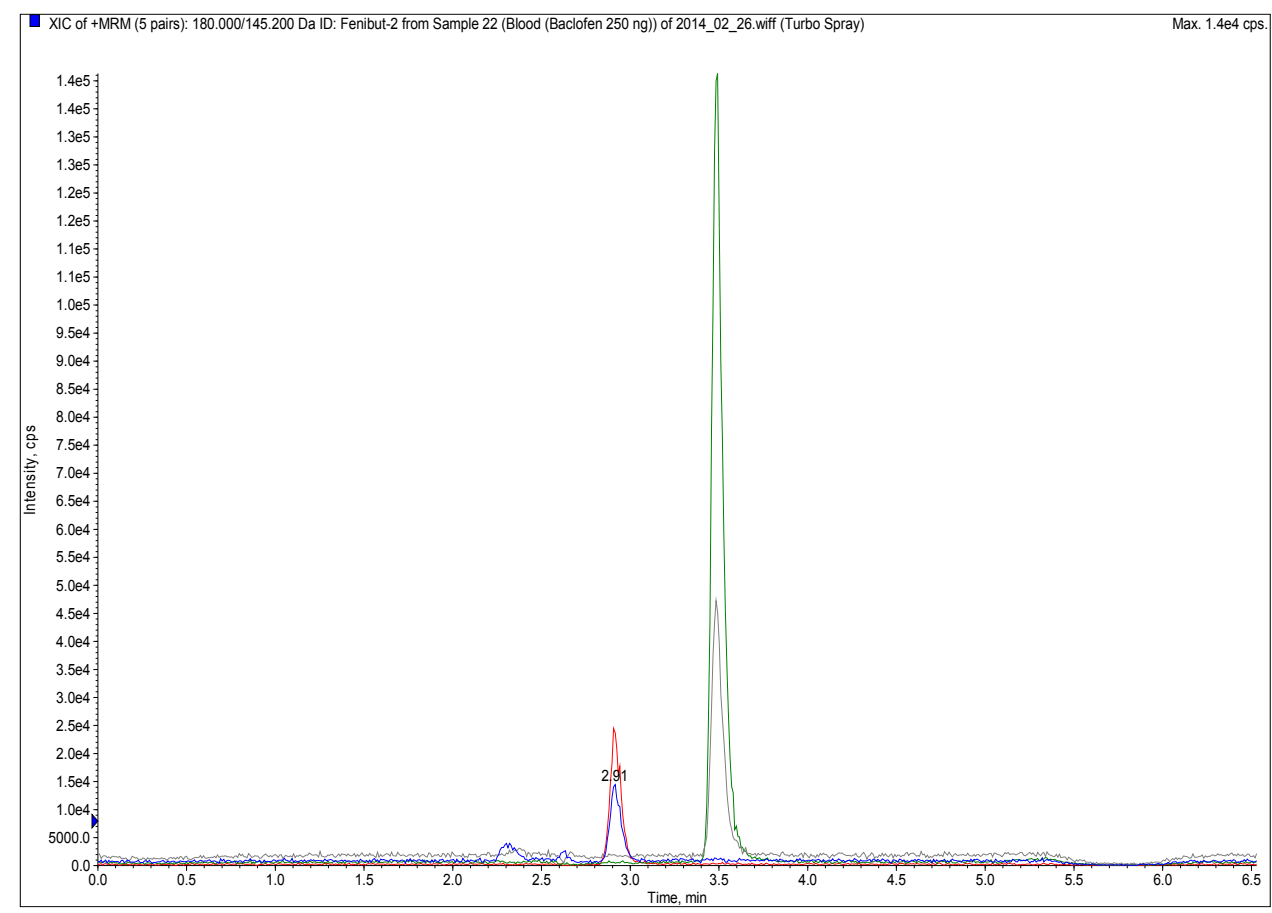

Рис. 2. Хроматограмма экстракта крови, содержащей баклофен, концентрация баклофена 250 нг/мл

количественного определения (5 нг/мл) и небольшим временем проведения анализа. Уравнение зависимости аналитического сигнала от концентрации баклофена в крови имеет вид $\mathrm{y}=0,0232 \mathrm{x}+0,0931$, коэффициент корреляции 0,9997 . Оценку правильности и повторяемости методики проводили методом «введено-найдено» по одиннадцати концентрационным уровням (от 50 до 4000 нг/мл) градуировочного графика в трех параллельных измерениях, отклонение от истинного значения находится в пределах до $5 \%$.

Разработанные методики применяли для определения баклофена в реальных образцах крови и мочи, полученных от лиц, поступавших в течение 2013 г. в отделение острых отравлений Красноярской межрайонной клинической больницы скорой медицинской помощи № 6 им. Н.С. Карповича (КМКБСМП) с предварительным диагнозом отравление лекарственными средствами и клиническими симптомами, характерными для отравления баклофеном, а также от трупов, поступивших в Красноярское краевое бюро судебно-медицинской экспертизы (ККБСМЭ) с подозрением на отравление баклофеном. Результаты исследования объектов приведены в табл. 2.

За 2013 г. в отделении острых отравлений КМКБСМП зафиксировано 21 случай отравления баклофеном, что подтверждено результатами химико-токсикологического исследования крови и мочи пациентов, а также клиническими признаками, характерными для отравления баклофеном.

В нескольких случаях наряду с баклофеном в моче пациентов обнаружилось присутствие других лекарственных и наркотических препаратов, таких как парацетамол, метаклопрамид, амфетамин и др. Концентрация баклофена в моче варьируется в диапазоне 3,3-549,9 мкг/мл. 
Olga A. Dukova, Efim A. Krasnov... The Possibility of Using Different Variants HPLC in Determining Baclofen...

Таблица 2. Результаты исследования биожидкостей лиц, поступивших в отделение острых отравлений с подозрением на отравление баклофеном

\begin{tabular}{|c|c|c|c|}
\hline \multirow{2}{*}{ № } & \multirow{2}{*}{ Дата поступления } & \multicolumn{2}{|c|}{ Концентрация баклофена, мкг/мл } \\
\hline & & кровь & моча \\
\hline 1 & 11.02 .13 & 0.078 & 540.5 \\
\hline 2 & 12.02 .13 & 0.048 & 92.3 \\
\hline 3 & 24.02 .13 & 0.112 & 57.8 \\
\hline 4 & 17.03 .13 & 1.120 & 89.9 \\
\hline 5 & 23.03 .13 & 0.032 & 34.9 \\
\hline 6 & 29.03 .13 & 0.112 & 70.5 \\
\hline 7 & 29.03 .13 & 0.082 & 59.7 \\
\hline 8 & 10.04 .13 & 2.530 & 241.1 \\
\hline 9 & 13.04 .13 & - & 3.3 \\
\hline 10 & 14.05 .13 & 0.150 & 18.9 \\
\hline 11 & 21.06 .13 & 0.824 & 100.8 \\
\hline 12 & 19.07 .13 & 0.613 & 47.2 \\
\hline 13 & 29.08 .13 & 0.596 & 6.0 \\
\hline 14 & 17.09 .13 & 0.373 & 549.9 \\
\hline 15 & 20.11 .13 & 0.762 & 144.3 \\
\hline 16 & 20.11 .13 & 0.601 & 97.5 \\
\hline 17 & 25.11 .13 & - & 11.6 \\
\hline 18 & 25.12 .13 & 0.667 & - \\
\hline 19 & 25.12 .13 & 0.748 & - \\
\hline 20 & 9.01 .14 & 0.826 & 107.8 \\
\hline 21 & 24.11 .13 & 0.234 & 40.8 \\
\hline
\end{tabular}

Концентрация баклофена в крови пациентов варьировалась в диапазоне 32-2530 нг/мл. Согласно литературным данным токсическая концентрация баклофена в сыворотке крови 1,1-3,5 мкг/мл [8-10]. В образцах 4 и 8 концентрация баклофена соответствует токсической.

\section{Выводы}

Исследования показали, что отравления баклофеном весьма распространены в г. Красноярске. Для уточнения и подтверждения диагноза отравления баклофеном необходим экспрессный химико-токсикологический анализ, что позволит определить тактику ведения пациентов, повысить качество лечения, а следовательно, и прогноз на выздоровление. Для исследования мочи на наличие баклофена разработана специфичная и экспрессная методика на основе ВЭЖХ-УФ. Для исследования крови на наличие баклофена и установление концентрации баклофена в крови необходим метод ВЭЖХ-МC/MC, так как его предел обнаружения значительно ниже. С помощью разработанных методик осуществлен химикотоксикологический анализ образцов крови и мочи от лиц с предварительным диагнозом отравление баклофеном. 


\section{Список литературы}

1. Машковский М. Д. Лекарственные средства. М.: Новая волна, 2010. 1216 с. [Mashkovsky M.D. The medicaments. Moscow: The New Wave, 2010. 1216 p. (In Russ.)]

2. Clarke's analysis of drugs and poisons. Edited by A. C. Moffat, M. D. Osselton and B. Widdop. London: Pharmac. Press, 2011. 2480 p.

3. Baselt R.C. Disposition of toxic drugs and chemicals in man. Foster city: Biomedical. Pub., 2009. 1720 p.

4. Spahn H., Kraub D., Mutschler E. Enantiospecific high-perfomance liquid chromatographic (HPLC) determination of baclofen and its fluoro analogue in biological material. Pharmac. Research 1988. Vol. 37 (2). P. 181-184.

5. Ersoy L., Tosunoglu S. Determination of baclofen in human plasma and urine by highperformance liquid chromatography with fluorescence detection. The Analyst 1995. Vol. 120 (2), P. 373-375.

6. Дукова О.А., Краснов Е.А., Ефремов А.А. Разработка ВЭЖХ-методики определения баклофена. Химико-фармацевтический журнал 2014. Т. 48 (10). C. 48-50. [Dukova O.A., Krasnov E.A., Efremov A.A. Development and validation of HPLC-method for determination of baclofen. Chemical Pharmaceutical Journal 2014. Vol. 48 (10). P. 48-50. (In Russ.)]

7. Дукова О.А., Краснов Е.А., Ефремов А.А., Шиврина Т.Г., Суворова Е.В. Определение баклофена в моче при химико-токсикологическом анализе // Вопросы биологической, медицинской и фармацевтической химии 2014. T. 12 (№ 3). C. 28-33. [Dukova O.A., Krasnov E.A., Efremov A.A., Shivrina T.G., Suvorova E.V. Determination of baclofen in the urine for chemical toxicological analysis. The question of biological, medical and pharmaceutical chemistry 2014. Vol. 12 (3). P. 28-33. (In Russ.)]

8. Haubenstock A., Hruby K., Jager U., Lenz K. Baclofen intoxication: report of 4 cases and review of the literature. Journal of toxicology. Clinical toxicology 1983. Vol. 20 (1). P. 59-68.

9. Fraser A.D., MacNeil W., Isner A.F. Toxicological analysis of fatal baclofen (Lioresal) ingestion. Journal of Forensic Sciences 1991. Vol. 36 (5). P. 1596-1602.

10. De Giovanni N., d'Aloja E. Death due to baclofen and dipyrone ingestion. Forensic Science International. 2001. Vol. 1263 (1). P. 26-32. 